\title{
SURFACE INTEGRITY IN TURNING OF FE17CR2NI0.2C IRON BASED THERMALLY SPRAYED COATINGS WITH SPECIAL RESPECT TO THE INFLUENCE OF THE FEED
}

\author{
H. Liborius ${ }^{1 *}$, A. Nestler ${ }^{1}$, G. Paczkowski², A. Schubert ${ }^{1}$, T. Grund ${ }^{2}$, T. Lampke ${ }^{2}$ \\ ${ }^{1}$ Chemnitz University of Technology, Professorship Micromanufacturing Technology, Chemnitz, Germany \\ ${ }^{2}$ Chemnitz University of Technology, Professorship of Materials and Surface Engineering, Chemnitz, Germany \\ *Corresponding author; e-mail: hendrik.liborius@mb.tu-chemnitz.de
}

\begin{abstract}
Cylinder linings of lightweight combustion engine blocks made from aluminium cast alloys are typically coated with thermally sprayed layers to enhance the chemical resistance. Finish machining of the cylinder linings is currently done by honing. A substitution of this process by machining with geometrically defined cutting edges would have significant advantages, especially concerning ecological aspects.

For the investigations Fe17Cr2Ni0.2C iron based coatings applicated by atmospheric plasma spraying on substrates, prepared with a dovetail microstructure are machined by turning. In the experiments the feed is varied in the range of $0.025 \mathrm{~mm}$ to $0.15 \mathrm{~mm}$. The tools used comprise CBN tips involving a rake angle of $0^{\circ}$. Tool wear and machining forces are determined. The geometrical properties of the machined surfaces are detected by tactile measurements, 3D laser scanning microscopy and SEM. The residual stresses are characterised by XRD.

An increase of the feed results in increasing components of the resultant machining force and higher values for Ra, Rz, Rpk, Rk and Rvk. Additionally, the amount of opened pores and pulled out coating material is reduced for high feeds. By increasing the feed the absolute values of the compressive principle stresses decrease.

The increase of the knowledge in machining of thermally sprayed coatings by tools with defined cutting edges contributes to a substitution of the honing process and hence enables a more material and energy efficient production.
\end{abstract}

\section{Keywords:}

Surface integrity; Thermally sprayed coatings; Turning

\section{INTRODUCTION}

Stricter regulations concerning the emission of $\mathrm{CO}_{2}$ and the overall objective of a reduced consumption of resources contribute to innovations in material development and machining processes. An approach to meet these environmental aims is the use of lightweight materials such as aluminium alloys. Depending on the field of application these alloys often do not exhibit sufficient physical or chemical resistance, and tribological properties. To combine the beneficial lightweight properties of aluminium alloys with adequate near-surface properties, material compounds are used. Hence, the characteristics of the substrate and the surface are partly decoupled.

An example for the automotive industry are thermally sprayed cylinder linings. To reduce the weight of combustion engine blocks, grey cast iron is substituted by an aluminium alloy as base material. These alloys do not have an appropriate chemical resistance against fuels with their additives. As a solution iron based thermally sprayed coatings are applied for cylinder linings, which can be produced by atmospheric plasma spraying (APS). To reach an adequate adhesive tensile strength between the substrate and the coating, the substrates have to be microstructured. After the subsequent additive process, the coatings exhibit surfaces with high roughness values. To meet the geometrical and surface requirements for the contact between the piston with its piston rings and the cylinder lining the coatings have to be machined. Finish machining is currently done by honing. This machining process with geometrically undefined cutting edges involves an opening of microstructure inherent pores of the coating, which act as lubricant reservoir in service. A substitution by finish boring would lead to less environmental pollution because of the avoidance of honing mud and maybe a shorter machining time.

Substrate microstructuring can be done by grit blasting, water jet cutting, laser machining, chemical machining, or processes with geometrically defined cutting edges. The different machining processes influence the adhesive tensile strength at the interface of the substrate and the coating. Furthermore, the substrate microstructure affects the morphology of the coating. Grit blasting is most commonly used for roughening of cylinder bores, because of the low costs and the short machining time. On the other side a cleaning step is necessary afterwards, because remaining grits at the substrates surface are detrimental for the whole compound. In contrast, water jet cutting includes the cleaning process. However, there are disadvantages such as high investment costs for the equipment. 
Additionally, the microstructured surfaces are inhomogeneous, which results in changes of the layer morphology. The generation of dovetail microstructures by turning offers higher adhesive tensile strengths than substrate roughening by grit blasting [Bobzin 2008]. Hoffmeister et al. [Hoffmeister 2008] showed an increase of the adhesive tensile strength with a raising dovetail structure height. However, a minimum height of $70 \mu \mathrm{m}$ was necessary for an interlocking between the substrate and the coating. A dovetail structure height of $75 \mu \mathrm{m}$ resulted in an adhesive tensile strength of $38 \mathrm{MPa}$ and the largest analysed height of $105 \mu \mathrm{m}$ in an adhesive tensile strength of $53 \mathrm{MPa}$. Liborius et al. [Liborius 2018] further analysed the influence of these dovetail microstructures. It has been shown that a decrease of the distance between the structure elements, which correlates to an increase of the number of structure elements per length led to a higher adhesive tensile strength. Additionally, the oxide proportion and the hardness raised.

Finish machining of iron based thermally sprayed coatings is mainly done by tools with undefined cutting edges. Machining processes with geometrically defined cutting edges are used for premachining. Therefore only less results for finish machining are published. Ding et al. [Ding 2012] analysed the influence of the cutting material on the tool wear in finish boring of iron based thermally sprayed coatings. In this experiments, the flank wear land width was measured after machining with cermet tools, diamond tipped tools, coated cemented carbide tools, and two different types of CBN (50\% boron nitride bounded by a ceramic binder and $90 \%$ boron nitride bounded by a metallic binder) tipped tools. The experimental setup was kept constant with a cutting speed of $300 \mathrm{~m} / \mathrm{min}$, a feed of $0.1 \mathrm{~mm}$, a depth of cut of $0.25 \mathrm{~mm}$, and a cutting length of $390 \mathrm{~m}$. The cermet tools showed the highest wear with a flank wear land width of about $2.1 \mathrm{~mm}$ after machining. Finish boring by the diamond tipped tools, the coated cemented carbide tools, and the CBN tipped tools with lower content of boron nitride resulted in similar flank wear land widths of about $1 \mathrm{~mm}$. The best performance regarding the tool wear was achieved for using the CBN tipped tools with $90 \%$ boron nitride, which entailed a significant reduction of the flank wear land width to $0.1 \mathrm{~mm}$. Further experiments with this cutting material showed less tool wear in the case of dry machining compared to the use of lubrication in the finish boring process.

Liborius et al. [Liborius 2019] analysed the influence of the cutting speed on the surface properties in turning of iron based thermally sprayed coatings. The cutting speed was varied in the range between $100 \mathrm{~m} / \mathrm{min}$ and $400 \mathrm{~m} / \mathrm{min}$. The depth of cut and the feed were kept constant with $0.05 \mathrm{~mm}$ respectively. Adequate geometrical surface properties were reached after machining with cutting speeds between $200 \mathrm{~m} / \mathrm{min}$ and $400 \mathrm{~m} / \mathrm{min}$. The cutting speed influenced the material separation and hence the proportion of pulled out particles or oxides and the proportion of opened pores at the machined surfaces. Tool wear was a problem in machining of the iron based thermally sprayed coatings. The results exhibited an increase of the tool wear with raising cutting speeds as a consequence of the increasing temperature in the shear zone and the increasing kinetic energy of the coating particles and oxides.

Regarding the state of the art, there are no investigations concerning the influence of the feed on the surface properties in turning of iron based thermally sprayed coatings. The mechanisms in the cutting process, e. g. for opening of pores have to be investigated. The influence of the feed on the properties of the surface layer is also not analysed yet. With the increased knowledge, a substitution of honing by finish boring seems to become possible. Additionally, the machining time may be reduced.

\section{EXPERIMENTAL SETUP AND METHODES}

\subsection{Substrate Microstructuring}

To analyse the mechanisms in the cutting process of thermally sprayed coatings a reproducible morphology of the coating is necessary. Comparing the different machining processes for substrate microstructuring, microstructuring by turning generates adequate geometrical substrate surface properties considering the adhesive tensile strength at the interface of substrate and coating and the morphology of the layer. The substrate preparation by turning with special tools with geometrically defined cutting edges enables the generation of reproducible and adjustable dovetail microstructures. The microstructure used in the experiments is shown in Fig. 1.

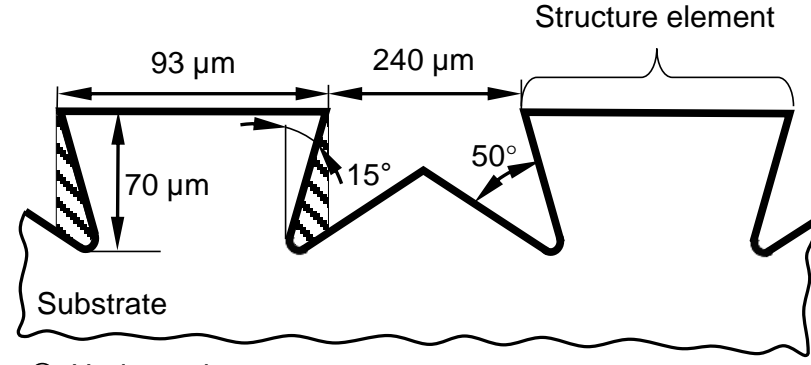

Q Undercutting area

Fig. 1: Geometry of the dovetail microstructure.

The microstructure is designed with a height of $70 \mu \mathrm{m}$. The width of $93 \mu \mathrm{m}$ in conjunction with the undercutting angle and the height of the structure element ensures a sufficient shear strength at the interface of the substrate and the structure elements. The undercutting angle of $15^{\circ}$ guarantees a high adhesive tensile strength as a result of the undercutting area. Additionally, this undercutting angle enables a filling of the undercuts with coating material (NiAl), which is improved by the high structure angle of $50^{\circ}$. The distance between the structure elements is $240 \mu \mathrm{m}$. Regarding the width of the structure elements, the number of structure elements per millimetre is 3 , which offers an undercutting area of about $3,700 \mu \mathrm{m}^{2} / \mathrm{mm}$ (determined at cross section in the feed direction).

For the experiments cylindrical specimens consisting of the aluminium alloy EN AW-5754 with a diameter of $50 \mathrm{~mm}$ and a length of $50 \mathrm{~mm}$ were used. The geometry of the specimens and the principle of the machining process are presented in Fig. 2. The microstructuring of the substrates by turning as well as the finish machining experiments (2.3) were carried out on a SPINNER PD 32 precision lathe. The centric through-hole with a diameter of $20 \mathrm{~mm}$ was used for clamping the specimens on a mandrel. 


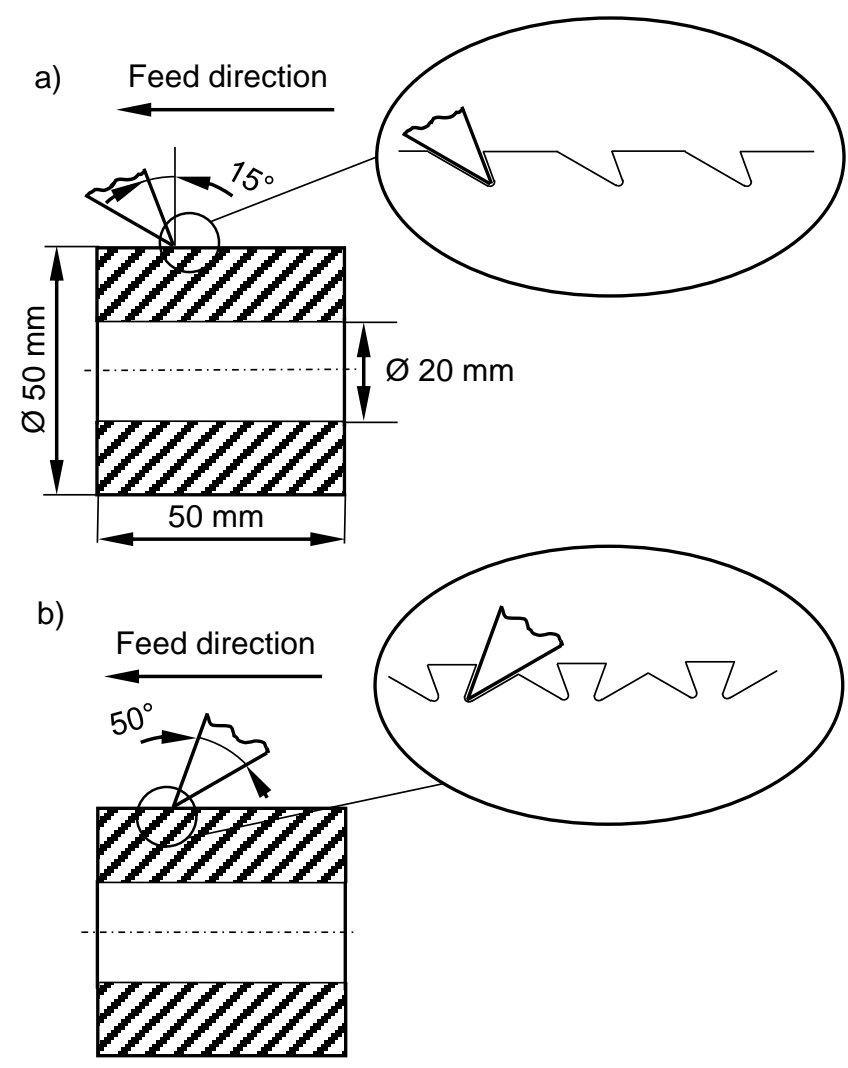

Fig. 2: Machining process of the microstructure: a) cutting the left side

b) cutting the right side of the structure element.

Microstructuring was done in two consecutive cutting cycles. First the left side of the dovetail structure element was manufactured and afterwards the right side. For both steps the machining parameters were equal. The rotational speed was kept constant with 1,275 $\mathrm{min}^{-1}$, which correlates to a cutting speed of about $200 \mathrm{~m} / \mathrm{min}$. This enables an adequate material separation and low tool wear. Additionally, an emulsion flood cooling was used to avoid built-up edge formation. The feed applied of $0.333 \mathrm{~mm}$ corresponds to the sum of the distance and the width of the structure elements. The height of $70 \mu \mathrm{m}$ of the structure elements was reached in 10 steps with a depth of cut of $7 \mu \mathrm{m}$. The small depth of cut was chosen to avoid tool breakage. The cutting corner of the special tools used is shown in Fig. 3.

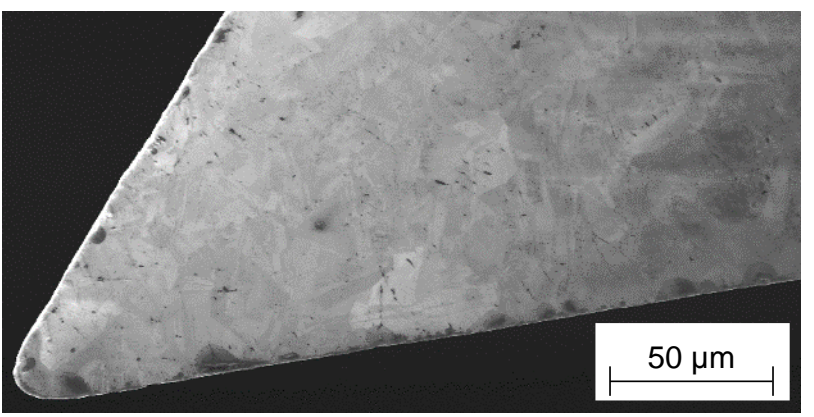

Fig. 3: CVD diamond tipped tool used for substrate microstructuring.

The CVD diamond tips were produced by laser machining. They are characterised by a corner radius of about $10 \mu \mathrm{m}$ and a corner angle of $50^{\circ}$, which complies with the structure angle with the same value. The undercutting angle was determined by the tool cutting edge angle, which was kept constant with $105^{\circ}$

\subsection{Coating process}

The coating of the substrates was done in two consecutive steps. On the substrate surface a primer coating (NiAl 80/20), with a thickness between $20 \mu \mathrm{m}$ and $40 \mu \mathrm{m}$, was applied by open-arc wire spraying (system: Perfect Spray - SMS Group). These layers are dense and have a low oxide proportion. The adhesion mechanisms at the interface to the substrate were interlocking and diffusion. Subsequently, the $\mathrm{FeCrNi}$ functional material (GTV $30.42 .2 ;-90+45 \mu \mathrm{m}$ ) was applied on the primer coating by atmospheric plasma spraying (APS) using a system of the brand F6 (GTV-Verschleißschutz $\mathrm{GmbH}$ ). The one anode cathode system is characterised by a high process stability and reproducibility of the coating properties. The thickness of the iron based coating was about $600 \mu \mathrm{m}$. The parameters for the APS coating process are summarised in Tab. 1.

Tab. 1: APS parameters for FeCrNi.

\begin{tabular}{cc}
\hline Parameter & Value \\
\hline Current $(\mathrm{A})$ & 640 \\
Power $(\mathrm{kW})$ & 40 \\
Plasma gas $(\mathrm{l} / \mathrm{min})$ & $\mathrm{Ar}: 60 / \mathrm{H}_{2}: 7$ \\
Powder feeding gas $(\mathrm{l} / \mathrm{min})$ & $\mathrm{Ar}: 3$ \\
Line spacing of the robot $(\mathrm{mm})$ & 8 \\
Coating distance $(\mathrm{mm})$ & 130 \\
Coating angle & $75^{\circ}$ \\
Speed of the robot $(\mathrm{mm} / \mathrm{s})$ & 10 \\
Rotational speed $\left(\mathrm{min}^{-1}\right)$ & 120 \\
Number of passages & 6 \\
\hline
\end{tabular}

\subsection{Machining process}

After the APS process the specimens exhibited a high roughness $(R z=72 \mu \mathrm{m}, \mathrm{Rt}=100 \mu \mathrm{m}$, mean values out of three tactile measurements according to 2.4.). To ensure constant conditions for the machining experiments a premachining by several cutting steps was done.

For the investigations the depth of cut was kept constant with $0.05 \mathrm{~mm}$. The cutting speed was chosen in accordance to previous experiments [Liborius 2019] with $200 \mathrm{~m} / \mathrm{min}$ as a compromise of tool wear and surface properties and to reduce the effect of tool wear on the results. The influence of the feed $(0.025 \mathrm{~mm}, 0.05 \mathrm{~mm}, 0.075 \mathrm{~mm}, 0.1 \mathrm{~mm}$, $0.125 \mathrm{~mm}$, and $0.15 \mathrm{~mm}$ ) was analysed (the unit $\mathrm{mm}$ corresponds to $\mathrm{mm} / \mathrm{rev}$ ). No lubrication was applied.

Indexable inserts of the type CCGW 09T304 (Sumitomo) with CBN tips were used for the turning experiments. The cutting material consists of $90 \%$ to $95 \%$ boron nitride with a grain size of about $1 \mu \mathrm{m}$, bounded with a cobalt based binder. The cutting edges had no chamfer, resulting in a rake angle of $0^{\circ}$. The tool holder used led to a nominal tool cutting edge angle of $95^{\circ}$. To detect the components of the resultant force the tool holder was mounted on the threeaxis force dynamometer Kistler, type 9257A, which was connected to a charge amplifier (Kistler 5070A).

The tool wear was detected by light microscopy and SEM after machining each specimen using a Keyence VHX-100 $3 \mathrm{D}$ microscope and a Zeiss EVO 25 scanning electron microscope. Additionally, the tool wear was analysed by 3D laser scanning microscopy using a Keyence microscope type VK-9700. 


\subsection{Surface properties}

\section{Surface structure}

The geometrical surface properties were detected by tactile and optical methods. The surface roughness of all specimens machined was measured in the feed direction using a stylus instrument Mahr type LD 120. The stylus was characterised by a radius of $2 \mu \mathrm{m}$ and an included angle of $90^{\circ}$. The measuring length was $4 \mathrm{~mm}$. The filtering of the profile was done in accordance to ISO 11562. For a validation of the roughness values, each specimen was measured at three different positions. In addition, details of the specimen were measured with a 3D laser scanning microscope Keyence type VK-9700. The size of the measured area was $2.0 \mathrm{~mm}$ (in the feed direction) $\times 0.5 \mathrm{~mm}$ (in the cutting direction). The objective of the optical measurements was to determine the volume of the pores and the material pulled out of the surface. For this, the software MountainsMap was used. To determine the valley void volume as accurately as necessary, first a form filter (polynomial $2^{\text {nd }}$ order) was applied. Afterwards, the periodic kinematic roughness profile was removed from the surface (using the tool "line orientation"). The Abbott curve of the resulting surface was characterised by a small core roughness. Following this, the tangent in this area had a small slope. Therefore, the lower material ratio (Smr2) was determined, which gave an approximated and reproducible value for the proportion of pores and pulled out material. The Smr2 was used as boundary for calculating the valley void volume (Vvv). Additionally, the machined surfaces were analysed by SEM using a Zeiss EVO 25 scanning electron microscope.

\section{Residual stresses}

The residual stresses in the machined surface layer were determined by X-ray diffraction utilizing the $\sin ^{2} \Psi$ method (diffractometer D8 Discover, Bruker AXS). The measurements were done with a cobalt anode on the $\{310\} /\{301\}$ lattice planes of martensite using Young's modulus $\mathrm{E}\{310\}=181 \mathrm{GPa}$ and Poisson's ratio $\mathrm{n}\{310\}=$ 0.32 . An area with a diameter of about $0.7 \mathrm{~mm}$ was irradiated.

\section{RESULTS AND DISCUSSION}

\subsection{Forces in the machining process}

In Fig. 4 the components of the resultant force are presented for finish turning considering different feeds. The forces occur as a result of friction and deformation while machining.

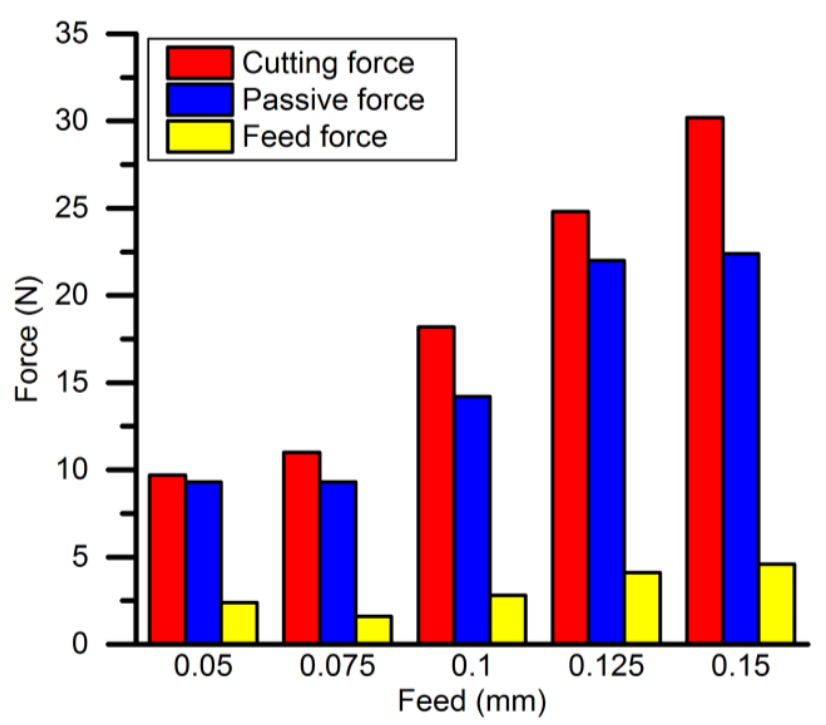

Fig. 4: Influence of the feed on the components of the resultant force.

The values represent the mean values of each experiment, which were calculated in the range of nearly constant cross section of undeformed chip (entering of the tool in the specimen and the exit of the tool are disregarded).

The three components of the resultant force raise with increasing feed, resulting from the increasing cross section of undeformed chip, shown in Tab. 2. The cutting forces represent the highest components with mean values between $9.7 \mathrm{~N}$ and $30.2 \mathrm{~N}$. The passive forces follow the same qualitative trend with mean values between $9.3 \mathrm{~N}$ and $22.4 \mathrm{~N}$. The feed forces are smaller with mean values between $1.6 \mathrm{~N}$ and $4.6 \mathrm{~N}$.

Tab. 2: Cross section of undeformed chip depending on the feed.

\begin{tabular}{cc}
\hline Feed $(\mathbf{m m})$ & $\begin{array}{c}\text { Cross section of } \\
\text { undeformed chip }\left(\boldsymbol{\mu \mathbf { m } ^ { 2 } )}\right.\end{array}$ \\
\hline 0.025 & 1,250 \\
0.05 & 2,500 \\
0.075 & 3,750 \\
0.1 & 5,000 \\
0.125 & 6,250 \\
0.15 & 7,500 \\
\hline
\end{tabular}

In the experimental investigations with the lowest feed $(0.025 \mathrm{~mm})$ the cross section of undeformed chip was only $1,250 \mu^{2}$. In this case, the lowest mean values of the components of the resultant force were expected, but due problems with the measuring system, they were not recorded. For machining with a feed of $0.05 \mathrm{~mm}$ the mean value of the cutting force was $9.7 \mathrm{~N}$. While machining with a feed of $0.075 \mathrm{~mm}$ the mean value of the cutting force was $11 \mathrm{~N}$. For higher feeds there was an almost linear increase of the cutting forces. A feed of $0.15 \mathrm{~mm}$ resulted in the the highest cross section of undeformed chip $\left(7,500 \mu \mathrm{m}^{2}\right)$. Hence the highest mean value of the cutting force $(30.2 \mathrm{~N})$ was measured.

The passive force is orientated perpendicular to the machined surface. Thereby this force component has a strong influence on the near-surface properties. The passive force raised with increasing feed, but the effective contact area of the specimen and the tool increased also. 
Consequently, the contact length of the specimen and the tool was regarded, shown in Fig. 5.

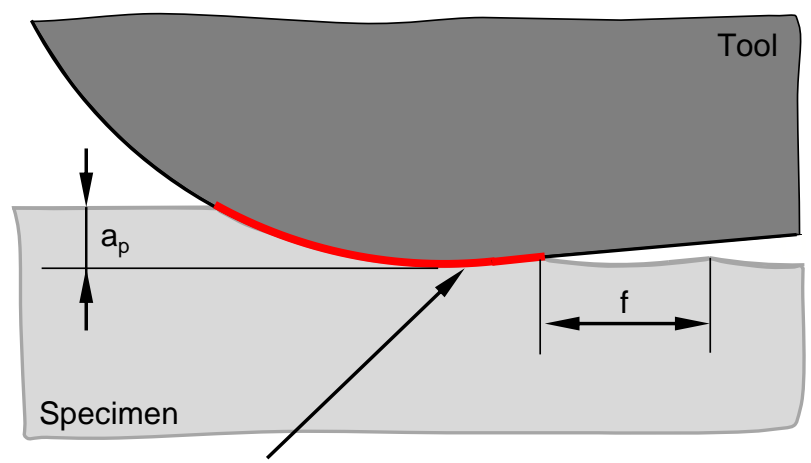

Contact length of specimen and tool

Fig. 5: Contact length of specimen and tool.

This parameter does not regard the contact between flank face and specimen, which changes as a consequence of increasing tool wear. The contact length of specimen and tool raises with increasing feed, shown in Tab. 3 .

Tab. 3: Influence of the feed on the contact length of specimen and tool and the ratio between passive force and the contact length of specimen and tool.

\begin{tabular}{ccc}
\hline $\begin{array}{c}\text { Feed } \\
(\mathbf{m m})\end{array}$ & $\begin{array}{c}\text { Contact } \\
\text { length of } \\
\text { specimen and } \\
\text { tool (mm) }\end{array}$ & $\begin{array}{c}\text { Ratio between passive } \\
\text { force and contact } \\
\text { length of specimen and } \\
\text { tool (N/mm) }\end{array}$ \\
\hline 0.05 & 0.227 & 41 \\
0.075 & 0.240 & 39 \\
0.1 & 0.254 & 56 \\
0.125 & 0.269 & 82 \\
0.15 & 0.285 & 79 \\
\hline
\end{tabular}

Regarding the ratio between the passive force and the contact length of specimen and tool it can be seen, that with increasing feed, the passive force per length also raised.

\subsection{Tool wear}

Regarding the feeds of $0.025 \mathrm{~mm}, 0.05 \mathrm{~mm}, 0.075 \mathrm{~mm}$, and $0.1 \mathrm{~mm}$ nearly no tool wear was visible. Raising feeds led to increasing flank wear land widths. In Fig. 6 the tool wear at the flank face and rake face after machining with a feed of $0.15 \mathrm{~mm}$ is shown.

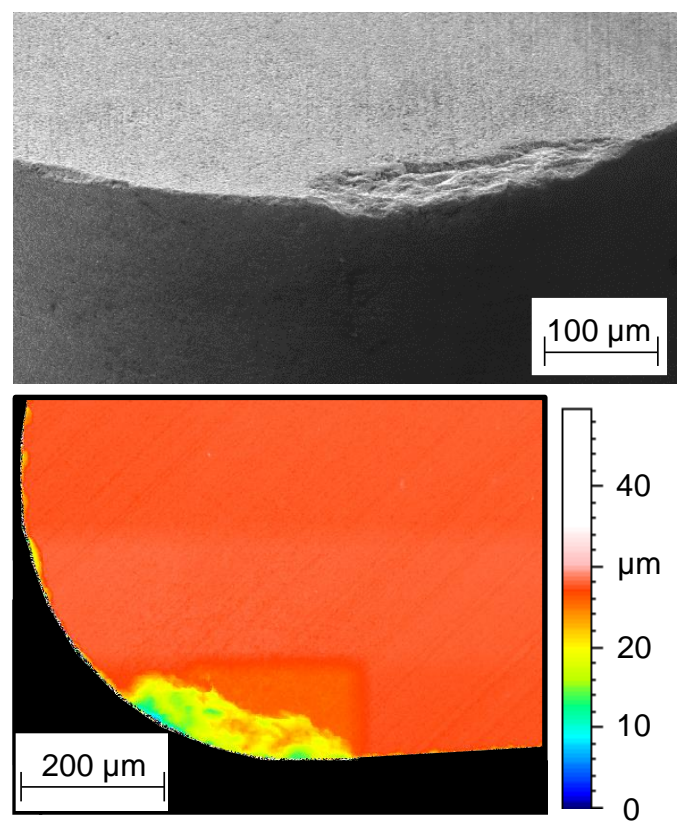

Fig. 6: Tool wear after machining with a feed of $0.15 \mathrm{~mm}$ detected by SEM (up) and 3D laser scanning microscopy (down).

The flank wear land width after machining the respective specimens with a feed of $0.125 \mathrm{~mm}$ and $0.15 \mathrm{~mm}$ was about $15 \mu \mathrm{m}$ for each of the both tools used. Increasing the feed resulted in higher components of the resultant force and temperatures in the shear zone, which led to higher tool wear. On the other side the contact time between the tool and the specimen decreased, which reduced the tool wear. Considering for every feed only one specimen was machined, stresses, temperatures, and contact time result in nearly no tool wear for machining with feeds up to 0.1 $\mathrm{mm}$. For higher feeds, the influence of the forces and temperature increased resulting in the higher tool wear. Considering the tool wear feeds up to $0.1 \mathrm{~mm}$ are beneficial for machining of thermally sprayed iron based coating.

\subsection{Surface structure}

The machined surfaces were characterised by feed marks. Independent of the feed all surfaces showed microcracks, opened pores and areas, where the material was pulled out. As an example a surface machined with a feed of $0.1 \mathrm{~mm}$ is shown in Fig. 7.

Area, where material is pulled out

Microcracks

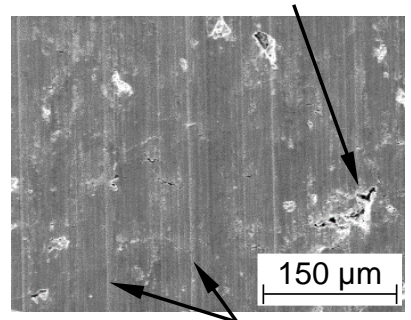

Feed marks

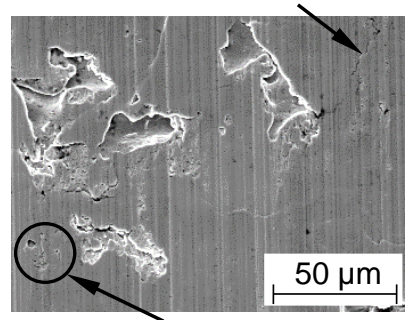

Opened pores
Fig. 7: Machined surface $(f=0.1 \mathrm{~mm})$ detected by SEM with two different magnifications.

In Fig. 8 the influence of the feed on the surface parameters $R a, R z, R p k, R v k$ and $R z$ is shown. The values are the mean values out of three tactile measurements. The respective minimum and maximum represent the highest and lowest value of the three measurements. 


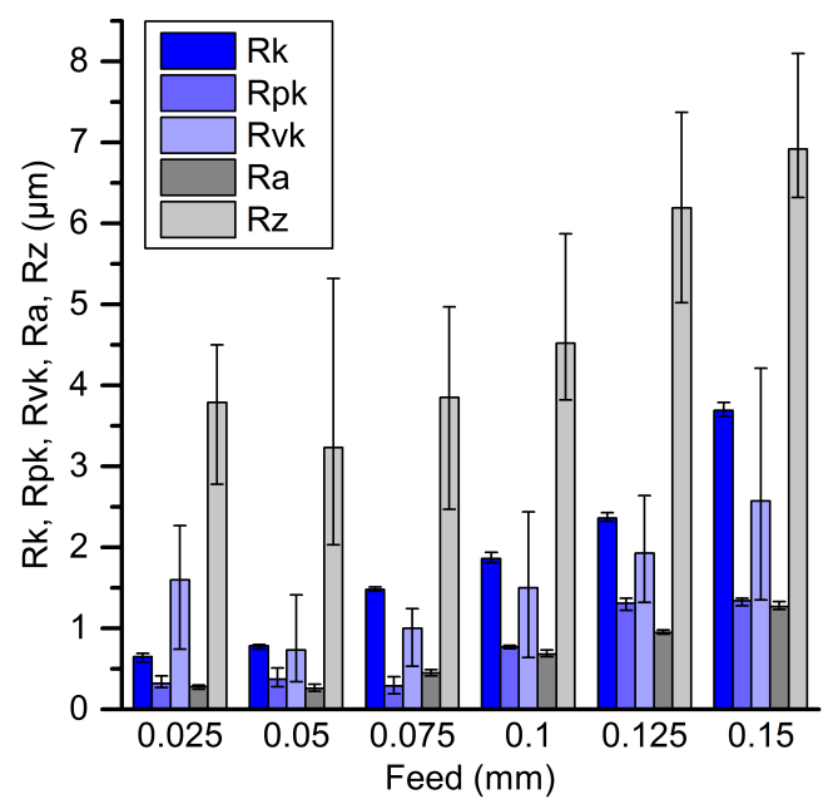

Fig. 8: Influence of the feed on Ra, Rk, Rpk, Rvk, and Rz.

The surface parameters regarded show a similar qualitative trend. With increasing feed $\mathrm{Ra}, \mathrm{Rk}, \mathrm{Rvk}, \mathrm{Rpk}$, and $\mathrm{Rz}$ increase.

The lowest mean values of $\mathrm{Ra}$ were reached after machining with the two lowest feeds $(0.028 \mu \mathrm{m}, 0.026 \mu \mathrm{m})$. Both values were similar. Increasing feeds resulted in increasing roughness values. The maximum mean value $(1.27 \mu \mathrm{m})$ was reached after machining with the highest feed. These values correlate qualitatively to $\mathrm{Rz}$. After machining with the lowest feed the mean value for $R z$ was $3.79 \mu \mathrm{m}$. The minimum was reached for the surface machined with a feed of $0.05 \mathrm{~mm}(3.29 \mu \mathrm{m})$. Increasing feeds again led to increasing roughness values. The maximum mean value of $6.92 \mu \mathrm{m}$ was a result of turning with the highest feed.

The increasing mean values for $R a$ and $R z$ can be explained by the higher kinematic roughness with raising feed. It has to be considered that $R z$ is much higher than the calculated kinematic roughness $\left(R z_{\text {kin }}\right)$ shown in Tab. 4.

Tab. 4: Influence of the feed on $R z$ kin and $R z$ (mean value).

\begin{tabular}{ccc}
\hline Feed $(\mathbf{m m})$ & Rzkin $(\boldsymbol{\mu m})$ & Rz $(\boldsymbol{\mu m})$ \\
\hline 0.025 & 0.2 & 3.79 \\
0.05 & 0.78 & 3.23 \\
0.075 & 1.76 & 3.85 \\
0.1 & 2.97 & 4.52 \\
0.125 & 4.29 & 6.19 \\
0.15 & 5.71 & 6.92 \\
\hline
\end{tabular}

For the two lowest feeds the kinematic roughness is calculated by:

$$
R z_{k i n} \approx f^{2} /\left(8 \cdot r_{\varepsilon}\right)
$$

For the higher feeds, the minor cutting edge gets in contact. The kinematic roughness is calculated by:

$$
\begin{aligned}
& R z_{k i n}=r_{\varepsilon} \cdot\left(1-\cos \kappa_{r}{ }^{\prime}\right)+f \cdot \tan \kappa_{r}{ }^{\prime} \cdot \cos ^{2} \kappa_{r}{ }^{\prime} \\
& \left(1 \pm \sqrt{\frac{2 \cdot r_{\varepsilon} \cdot \sin \kappa_{r}{ }^{\prime}}{f \cdot \cos ^{2} \kappa_{r}{ }^{\prime}}}-\tan ^{2} \kappa_{r}{ }^{\prime}\right)
\end{aligned}
$$

The differences between $\mathrm{Rz}$ and $\mathrm{R} \mathrm{z}_{\mathrm{kin}}$ are a result of pulled out coating particles and oxides as well as opened pores, which are not addressed in the equations.

Regarding the five surface parameters merely for Rk $(0.65 \mu \mathrm{m})$ the minimum is reached for machining with the smallest feed. Increasing the feed resulted in significantly increasing values for Rk. The maximum was reached after machining with the highest feed with $3.69 \mu \mathrm{m}$. The mean values for Rpk did not change significantly for the respective machining process of the three specimens with three lowest feeds. The minimum of Rpk was reached after machining with a feed of $0.075 \mathrm{~mm}$ with a mean value of $0.29 \mu \mathrm{m}$. For increasing feeds Rpk increased and reached a maximum of $1.34 \mu \mathrm{m}$ after machining with the highest regarded feed. The raise of the mean values with increasing feed can be explained by the higher kinematic roughness, which also led to an increase of Rk and Rpk.

The most interesting parameter of the Abbott curve in machining of the thermally sprayed coatings is Rvk. It enables the characterisation of the oil retention volume of the surface. After machining with the smallest feed the mean value for Rvk was $1.6 \mu \mathrm{m}$. The minimum of this parameter was reached after machining with a feed of $0.05 \mathrm{~mm}(0.73 \mu \mathrm{m})$. Higher feeds resulted in increasing mean values. After machining with a feed of $0.1 \mathrm{~mm} \mathrm{Rvk}$ was similar as in the case of the smallest feed $(1.5 \mu \mathrm{m})$. After machining of the thermally sprayed coating with a feed of $0.15 \mathrm{~mm}$ the maximum mean value for Rvk was determined with $2.57 \mu \mathrm{m}$.

Rvk is influenced by opened pores and pulled out coating material. Additionally, this parameter is also affected by the height of the kinematic roughness profile. The feed influences this kinematic roughness directly. Hence, Rvk is not useful to determine the oil retention volume of thermally sprayed coatings machined with different feeds by the tools used. Additional parameters have to be considered to determine the proportion of opened pores and pulled out coating material. Consequently, the parameter $\mathrm{Vvv}$ is used determined in accordance to the filtering described in section 2.4. The influence of the feed on Vvv is shown in Fig. 9.

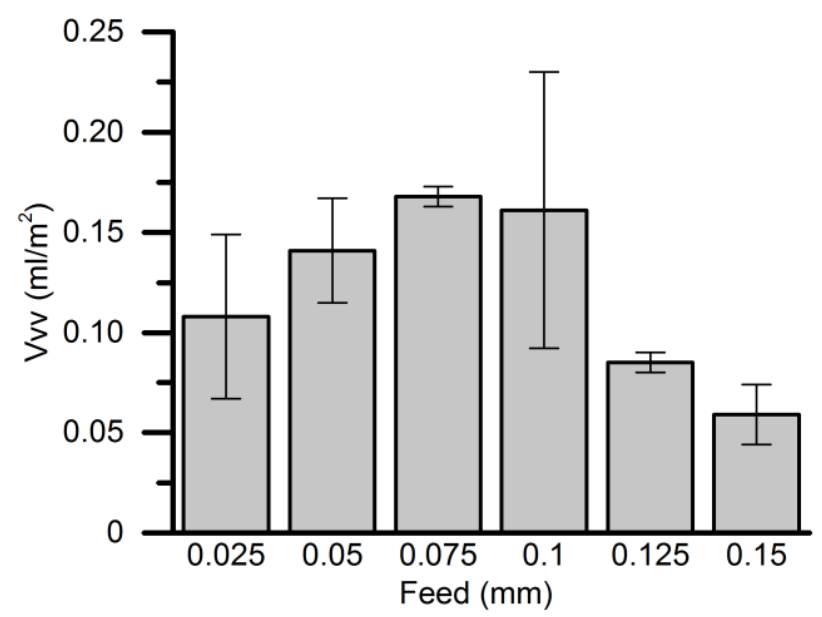

Fig. 9: Influence of the feed on Vvv (valley void volume). 
The values shown are the mean values of two measurements. The respective minimum and maximum represent the higher and lower value of two single measurements. With raising feed the mean values for $\mathrm{Vvv}$ increased. The maximum was reached for the surface machined with a feed of $0.1 \mathrm{~mm}\left(0.168 \mathrm{ml} / \mathrm{m}^{2}\right)$. Considering the variance of the mean values for the surfaces machined with feeds up to $0.1 \mathrm{~mm}$, no clear trend for Vvv appeared for these specimens. Although, only regarding the mean values, a tendency of increasing values was visible. For the mean values of $V v v$ after machining with a feed of $0.125 \mathrm{~mm} \quad\left(0.085 \mathrm{ml} / \mathrm{m}^{2}\right)$ and $0.15 \mathrm{~mm} \quad\left(0.059 \mathrm{ml} / \mathrm{m}^{2}\right)$ a decrease of $V v v$ compared to the lower feeds exists. This can be explained by the higher deformation of the surface as a result of the increasing components of the resultant force. Thereby less particles at the substrate surface are pulled out and fewer pores are opened. The ratio between the passive force and the contact length of tool and specimen confirms this.

\subsection{Properties of the surface layer}

\section{Connection of substrate und coating}

After machining all specimens were analysed in cross sections. An example, machined with a feed of $0.15 \mathrm{~mm}$, is given in Fig. 10.

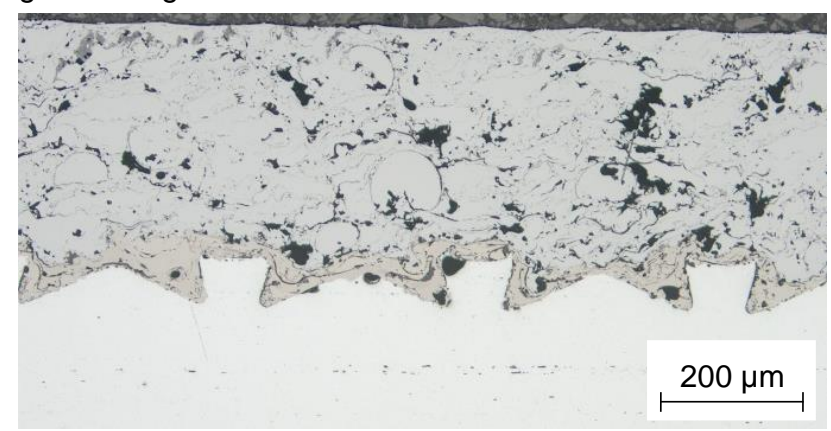

Fig. 10: Coated specimen machined with a feed of $0.15 \mathrm{~mm}$ in cross section.

Even after machining with the highest feed and accordingly the highest components of the resultant force the substrate microstructure offers an adequate adhesive strength between substrate and coating. No deformation of the substrate dovetail microstructure is visible. Additionally, there are no significant cracks at the interface of the substrate and the coating or inside the coating.

\section{Residual stresses}

The residual stresses are measured at the machined surfaces using XRD. The first and second principle stress depending on the feed are shown in Tab. 5. The directions of the first and second principle stress are shown in Fig. 11
Tab. 5: Influence of the feed on the first and second principle stress.

\begin{tabular}{cccc}
\hline $\begin{array}{c}\text { Feed } \\
(\mathbf{m m})\end{array}$ & $\begin{array}{c}\text { First principle } \\
\text { stress s1 } \\
(\mathbf{M P a})\end{array}$ & $\begin{array}{c}\text { Second } \\
\text { principle stress } \\
\text { s2 (MPa) }\end{array}$ & $\begin{array}{c}\text { Angle of } \\
\mathbf{s}_{1} \text { to the } \\
\text { x-axis }\end{array}$ \\
\hline 0.025 & $-144 \pm 15$ & $141 \pm 12$ & $25^{\circ}$ \\
0.05 & $-160 \pm 20$ & $75 \pm 15$ & $40^{\circ}$ \\
0.075 & $-109 \pm 16$ & $87 \pm 12$ & $49^{\circ}$ \\
0.1 & $-65 \pm 22$ & $90 \pm 15$ & $39^{\circ}$ \\
0.125 & $-38 \pm 17$ & $106 \pm 12$ & $21^{\circ}$ \\
0.15 & $-132 \pm 12$ & $63 \pm 10$ & $69^{\circ}$ \\
\hline
\end{tabular}

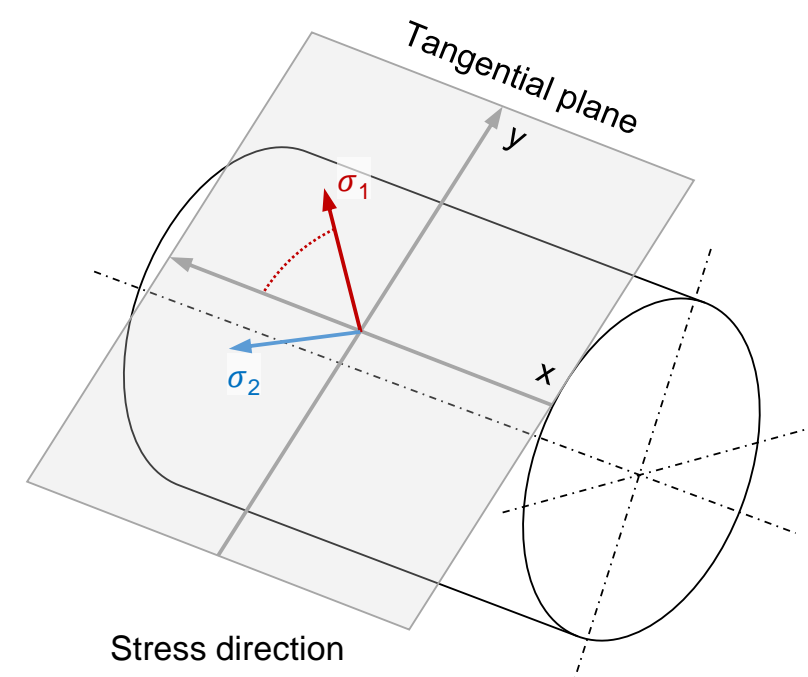

Fig. 11 : Direction of the first and second principle stress.

Subsequent to the thermal spraying process the residual stresses were measured at the as sprayed surface. The iron based coating was nearly free of residual stresses (first principle stress: $6 \mathrm{MPa}$ ). Independent of the feed, after machining compressive first principle stresses were detected at the surfaces. The highest absolute values were reached for machining with the small feeds with $-144 \mathrm{MPa}$ $(0.025 \mathrm{~mm})$ and $-160 \mathrm{MPa}(0.05 \mathrm{~mm})$. Increasing the feed up to $0.125 \mathrm{~mm}$ resulted in decreasing absolute values for the first principle stress to $-40 \mathrm{MPa}$. After machining with a feed of $0.15 \mathrm{~mm}$ the first principle stress was $-130 \mathrm{MPa}$. The value does not conform to the described trend. The decrease of the absolute values of the first principle stress can be explained by the higher temperatures in the shear zone as a result of the increasing cutting power, which led to smaller absolute values of the compressive residual stresses. Additionally, with increasing feed the components of the resultant force increased. Theoretically, this resulted in stronger compressive residual stresses subsequent to a raising amount of plastic deformation in the surface layer. But, with increasing feed the cutting force and the passive force affected at a larger area. The cutting force affected the cross section of undeformed chip and the passive force the contact length of tool and specimen. Hence, the influence of the feed on plastic deformation was minor compared the influence on the temperature. Thereby the values of the first principle residual stresses decreased. Although the residual stresses were only measured at the surface of the coatings, deeper layers of the coatings also influence the results. The intrusion depth of the X-ray radiation is about some micrometres. But, the deeper layers affect the measured residual stresses less than the nearsurface area. 


\section{SUMMARY AND CONCLUSIONS}

The results of the experimental investigations show that independent of the feed the chosen substrate microstructure generates an adequate adhesive strength at the interface of the substrate and the coating for the subsequent turning process. This is a consequence of the form fit between the structure elements and the coating material. Increasing the feed results in higher components of the resultant force. The tool wear also increases for high feeds. After the machining process the surfaces exhibit feed marks, microcracks, pulled out coating material and pores. Increasing feeds result in increasing values for Rk, Rpk, $\mathrm{Rvk}, \mathrm{Ra}$ and $\mathrm{Rz}$. However, the minimum is not always reached after machining with the lowest feed $(0.025 \mathrm{~mm})$. The maximum of the values is achieved for turning with the highest feed in the considered range $(0.15 \mathrm{~mm})$. The $\mathrm{Vvv}$ decreases for the two highest feeds, which is a result of higher ratios between passive force and contact length of specimen and tool and hence less opened pores and pulled out coating material at the machined surface. The finish machining process induces compressive residual stresses in the surface layer. The absolute value of the first principle stress decreases with increasing feed, excepting after machining with the highest feed.

The mechanism in finish turning of thermally sprayed coatings are transferable to finish boring. Although small changes are expected. For instance the differences between internal and external spraying process lead to variances of the coating properties. Additionally, the contact conditions between tool and workpiece are affected.

Further analyses by SEM, EBSD and microhardness measurements at cross sections are necessary the show the impact of the feed on the surface layer. Hence, changes in grain size, grain size distribution, grain orientation and hardness are visible. For enhancing the understanding of the machining of iron based thermally sprayed coatings experiments concerning the influence of the depth of cut and the rake angle are necessary to show the influence of these parameters on the surface properties and the tool wear. Furthermore, tribological experiments enable to exhibit the relations between surface properties, friction and wear.

The shown relations between feed and properties of the machined surface increase the knowledge in machining of thermally sprayed coatings. Considering the influence of the feed on the machining time a more economic manufacturing process is possible. This expedites the substitution of the common finish machining (honing) by processes with geometrically defined cutting edges.

\section{ACKNOWLEDGEMENTS}

The authors acknowledge the DFG (German Research Foundation) for supporting this work carried out within the project "Functional surface design by complementarily matched thermal spray and cutting processes" (SCHU 1484/19-1, LA 1274/38-1).

\section{REFERENCES}

[Bobzin 2008] Bobzin, K. et al. Thermal spraying of cylinder bores with the Plasma Transferred Wire Arc process. Surface \& Coatings Technology, April 2008, Vol. 202, pp. $4438-4443$

[Ding 2012] Ding, K., Sasahara, H. Study on the machining of Iron-Based Thermal Spray Coating for Sleeveless Engine Cylinder. Advanced Materials Research, February 2012, Vol. 472-475, pp. 991-996, ISSN 1662-8985

[Hoffmeister 2008] Hoffmeister, H. W., Schell, C. Mechanical roughing of cylinder bores in light metal crankcases. Production Engineering, June 2008, Vol. 2, pp. 365-370

[Liborius 2018] Liborius, $H$. et al. Influence of dovetail microstructures on adhesive tensile strength and morphology of thermally sprayed metal coatings, Procedia CIRP, 2018, Vol. 71, pp. 299-304

[Liborius 2019] Liborius, $\mathrm{H}$. et al. Influence of cutting speed on the surface properties in turning of $\mathrm{Fe} 17 \mathrm{Cr} 2 \mathrm{NiO} .2 \mathrm{C}$ iron based thermally sprayed coatings. In: D. Dimitrov, D. Hagedorn-Hansen, K. von Leipzig, ed. International Conference on Competitive Manufacturing (COMA 19) Proceedings, Stellenbosch, 30 January-1 February, 2019, Department of Industrial Engineering: Stellenbosch University, pp. 317-323, ISBN 978-0-7972-1779-9 